\title{
Article selection and anaphora in the German relative clause *
}

\author{
Julian Grove \\ University of Chicago
}

\author{
Emily Hanink \\ University of Chicago
}

\begin{abstract}
German definite articles are able to contract with prepositions under certain conditions. When a noun phrase is discourse anaphoric, contraction is blocked. In the current paper we present a puzzle: restrictive relative clauses require the use of the non-contracted (strong) article form, despite their apparent lack of anaphoricity; both the determiner of the head noun and the relative pronoun (which is, in most cases, homophonous with the definite article) surface with the strong form. We provide a uniform analysis of discourse anaphoric and relative clause uses that makes use of contexts, as defined in the dynamic framework of de Groote (2006). We argue that a lexical item, which we call "anaph", whose purpose is to make reference to an individual provided by the context, intervenes between the noun and the article in the strong form. anaph makes reference to an individual provided by the global context in cases of anaphora, and to an individual provided by an updated local context in the case of relative clauses.
\end{abstract}

Keywords: definite articles, relative clauses, anaphora, variable free, German

\section{Introduction}

Under certain circumstances, a definite article in German may contract with a proceeding preposition (in which case, the article is called "weak"). Such a case of contraction is shown in (1a), which can be compared with the non-contracted (i.e., "strong") article in (1b).

a. Hans ging zum Haus.

hans went to+the house

'Hans went to the house.'

b. Hans ging zu dem Haus.

hans went to the house

'Hans went to the house.'

* We thank Karlos Arregi, Rajesh Bhatt, Amy Rose Deal, Itamar Francez, Anastasia Giannakidou, Caroline Heycock, Chris Kennedy, Jason Merchant, Kjell Johann Sæbo, Florian Schwarz, and Ming Xiang for their invaluable feedback. We also thank the audiences at SALT 26, WCCFL 34, CLS 52, and the Linguistics and Philosophy Workshop at the University of Chicago. 
The distribution of weak and strong articles is analyzed in Schwarz 2009 as resulting from a contrast in presuppositions that relate to the common ground and the discourse. The weak article, according to Schwarz, has a presupposition that its referent is unique, while the strong article presupposes that its referent is anaphoric. As Schwarz notes, an analysis of the article in terms of discourse-related presuppositions has trouble accounting for a second environement in which the strong article appears - that of the relative clause. As (2) shows, a strong article appears in German relative clauses, both in the construction of the relative pronoun and as the matrix determiner.

(2) Fritz wohnt jetzt $\{$ in dem, \#im $\}$ Haus, \{von dem, ${ }^{*}$ vom $\}$ er fritz lives now in the in+the house from the from+the he schon seit Jahren schwärmt.

already since years raves

'Fritz now lives in the house that he has been raving about for years.'

As the environments in (2) do not appear at first glance to constitute cases requiring anaphora, it is puzzling that the definite article would be strong, given the classification just mentioned.

In the present paper, we attempt to give a solution to this puzzle. Our solution stems from the observation that the environment in (2) is similar to another type of environment that licenses anaphoric expressions, and that natural language is already rife with. This type of environment is the scope of a quantifier (or any other operator-like expression), in which an anaphoric expression can be interpreted as bound. To implement this analysis, we adopt the dynamic framework of de Groote (2006), who provides an analyis of quantificational expressions that assimilates bound readings of pronouns to anaphora. The framework is variable free and records possible referents for anaphora as a set that is passed along dynamically, and which quantificational and anaphoric expressions may modify and make reference to, respectively. We hope that the solution motivated here provides a means of holding onto the simple classification of Schwarz: the articles in the environments in (2) look anaphoric because they are. The solution we present also opens up the possibility that languages may make use of more than one strategy for forming (externally headed) relative clauses: either a more conventional strategy that gives them the syntax of a constituent question, or the strategy described here, which makes use of anaphora.

The paper goes as follows. In Section 2, we describe in somewhat more detail the distributions of the strong and weak definite articles. We include cases of anaphora to the discourse, as well as cases involving quantificational contexts. In Section 3, we give the analysis of the strong article in relative clauses as a grammar fragment presented in Combinatory Categorial Grammar (CCG) with Function Application 
Article selection and anaphora

and Function Composition. The semantics we provide is based on de Groote's formalism and makes use of contexts, i.e., sets of individuals. In Section 4, we show how the fragment can be adjusted to handle cases of discourse anaphora in a dynamic setting. In Section 5, we provide some additional structural evidence for the proposal. Finally, Section 6 concludes.

\section{The distribution of the definite articles}

Here, we exemplify some of the environments that the strong and weak German articles appear in. We start with the strong article.

\subsection{Environments manifesting the strong article}

The most basic type of environment for the strong article is that in which it is anaphoric to some indefinite antecedent, as in (3).

(3) Fritz wohnt seit Jahren in einem großen Haus. Er schärmt immer noch fritz lives since years in a big house he raves always still \{von dem, \#vom Haus. from the from+the house

'Fritz has lifted in a big house for years. He still raves about the house.'

As indicated, the weak form is unacceptable in this context. This unacceptability arises because the reference of the article is determined discursively via an antecedent (that provided by the indefinite).

Another type of environment in which the strong article appears is that in which the antecedent is related to the referent of the definite description by a relation provided by the meaning of the noun. Such cases exemplify what Schwarz calls "bridging". 1

(4) Das Theaterstïck missfiel dem Kritiker so sehr, dass er in seiner the play displeased the critic so much that he in his Besprechung kein gutes Haar \{ an dem, \#am $\}$ Autor ließ. review no good hair on the on+the author left

'The play displeased the critic so much that he tore the author to pieces in his review.'

(Schwarz 2009: 53, ex. 59)

These contexts also fall under the category of discourse anaphora, though the antecedents to the definite article are not mentioned explicitly. The referent of dem Autor is determined based on the antecedent provided by das Theaterstück.

1 These cases are called "associative anaphora” by Hawkins (1978). 
A third type of environment manifesting the strong article is that in which its interpretation covaries with that of a quantificational antecedent. This case, also from Schwarz, is exemplfied in (5).

(5) Jedes Mal, wenn ein Ornithologe im Seminar einen Vortrag hält, every time when an ornithologist in+the seminar a lecture holds wollen die Studenten \{von dem, \#vom Mann wissen, ob want the students of the of+the man know whether Vogelgesang grammatischen Regeln folgt. bird singing grammatical rules follow

'Every time an ornithologist gives a lecture in the seminar, the students want to know from the man whether bird songs follow grammatical rules.'

(Schwarz 2009: 33, ex. 31)

Such a case illustrates that the strong article is similar, distributionally, to a pronoun, in that it appears both in contexts in which its antecedent is referential and those in which it is quantificational. ${ }^{2}$ We now turn to the weak article.

\subsection{Environments manifesting the weak article}

The weak article appears with definite descriptions that lack an antecedent, and with which the strong article is therefore excluded. It can therefore be seen as the elsewhere form. One context in which the weak form appears, for example, is that in which the definite description refers to something in the immediate situation (Hawkins 1978).

(6) Das Buch, das du suchst, steht \{\#in dem, im $\}$ Glasschrank. the book that you look for stands in the in+the glass cabinet 'The book that you are looking for is in the glass cabinet.'

(Schwarz 2009: 39, ex. 40)

Other uses of the weak article are those in which the definite description refers to something in the larger situation or in the global situation (Hawkins 1978); these are illustrated in (7) and (8), respectively.

(7) Der Empfang wurde [\#von dem, vom $\}$ Bürgermeister eröffnet.

the reception was by the by+the mayor opened

'The reception was opened by the mayor.' $\quad$ (Schwarz 2009: 40, ex. 42)

2 Another environment in which the strong article appears is that in which the definite description functions as a demonstrative (see Schwarz 2009). We leave this case out for reasons of space. 
Article selection and anaphora

Armstrong flog als erster $\quad$ \#\#zu dem, zum $\}$ Mond. armstrong flew as first one to the to+the moon

'Armstrong was the first one to fly to the moon.'

(Schwarz 2009: 40, ex. 43)

Importantly, in none of these uses does the definite description have an antecedent, but its referent appears to be inferred based on contextual information about the common ground.

\subsection{The account of Schwarz (2009)}

We briefly sketch the account of Schwarz as a point of comparison with the account which we present in the next section. Schwarz analyzes the definite article as being constituted by three different cases: the weak form, the strong form, and the strong form as it occurs in bridging contexts (exemplified in (4) above). His account is cast within situation semantics (Barwise \& Perry 1983; Kratzer 1989, 1995, 1998, 2002; Elbourne 2005), so that the uniqueness presuppositions of the definite articles are only satisfied in particular situations. The denotations he gives to these forms of the article are as follows.

$$
\begin{aligned}
& \llbracket t h e_{\text {weak }} \rrbracket=\left(\lambda s_{\mathrm{s}} \cdot\left(\lambda P_{\mathrm{e} \rightarrow \mathrm{s} \rightarrow \mathrm{t}} \cdot\left(l x_{\mathrm{e}} \cdot P x s\right)\right)\right) \\
& \llbracket \text { the } e_{\text {strong }} \rrbracket=\left(\lambda s_{\mathrm{s}} \cdot\left(\lambda P_{\mathrm{e} \rightarrow \mathrm{s} \rightarrow \mathrm{t}} \cdot\left(\lambda y_{\mathrm{e}} \cdot\left(l x_{\mathrm{e}} \cdot P x \& x=y\right)\right)\right)\right) \\
& \llbracket \text { the } e_{\text {strong (bridging) }} \rrbracket=\left(\lambda s_{\mathrm{s}} \cdot\left(\lambda R_{\mathrm{e} \rightarrow \mathrm{e} \rightarrow \mathrm{s} \rightarrow \mathrm{t} \cdot(}\left(\lambda y_{\mathrm{e}} \cdot\left(l x_{\mathrm{e}} \cdot R y x s\right)\right)\right)\right)
\end{aligned}
$$

The denotation Schwarz gives to the weak form in (9) corresponds to a Strawsonian meaning in which there is a presupposition of existence and uniqueness (here, carried by the $l$-operator).

The denotation assigned to the strong article in (10) carries the same presupposition, but part of the descriptive content of the resulting definite is that its referent be identical to some other individual (the argument introduced by the binder ' $\lambda y_{\mathrm{e}}$ '). Correspondlingly, the syntax of the strong article has it combine with an index, so that this individual is inherited from a previously introduced discourse referent.

The denotation Schwarz assigns to the bridging version of the strong article, given in (11), likewise has it combine with an individual (that introduced by the binder ' $\lambda y_{\mathrm{e}}$ '), but this individual is only related to the referent of the resulting definite description by the meaning of the noun phrase (introduced by the binder ' $\lambda R_{\mathrm{e} \rightarrow \mathrm{e} \rightarrow \mathrm{s} \rightarrow \mathrm{t}}$ '). Such a denotation is meant to account for examples like (4), repeated here. 
(4) Das Theaterstück missfiel dem Kritiker so sehr, dass er in seiner the play displeased the critic so much that he in his Besprechung kein gutes Haar \{ an dem, \#am $\}$ Autor ließ. review no good hair on the on+the author left

'The play displeased the critic so much that he tore the author to pieces in his review.'

(Schwarz 2009: 53, ex. 59)

dem Autor would then be interpreted as follows.

$$
\begin{aligned}
& \llbracket[[1 \text { dem }] \text { Autor }] \rrbracket^{g}= \\
& \left(\lambda s_{\mathrm{e}} \cdot(11) s \llbracket \text { Autor } \rrbracket^{g} g(1)\right)= \\
& \left(\lambda s_{\mathrm{s}} \cdot\left(l x_{\mathrm{e}} \cdot \text { author } g(1) x s\right)\right)
\end{aligned}
$$

If (12) is embedded in the sentence in (4), it can be interpreted as (a function from situations to) the unique author of the play, assuming 1 is the discourse referent corresponding to the play.

As we will show, Schwarz's system can be improved in two respects. On the one hand, Schwarz provides three definite articles: one weak form and two strong forms. On the other hand, none of the denotations he provides accounts for the appearance of strong articles in relative clauses, as we illustrated above with the example in (2), repeated here.

(13) Fritz wohnt jetzt $\{$ in dem, \#im $\}$ Haus, \{von dem, *vom $\}$ er fritz lives now in the in+the house from the from+the he schon seit Jahren schwärmt.

already since years raves

'Fritz now lives in the house that he has been raving about for years.'

In the following section, we provide an analysis of relative clauses that accounts for their coincidence with the strong article.

\section{Solution}

We give an analysis of relative clauses cast within $\mathrm{CCG}$ - but with an added rule to handle extraposition of adjuncts - and the semantic framework for binding and anaphora of de Groote 2006. First, we introduce the syntactic framework we will use. We will make use of the following rules, given here in sequent style presentation.

\section{(14) Axiom rule}

$$
\overline{\langle\mathrm{A}, \llbracket \mathrm{A} \rrbracket\rangle \vdash \tau(\mathrm{A})} \mathrm{Ax}
$$


Article selection and anaphora

\section{(15) Function application}

$$
\begin{gathered}
\frac{\langle\mathrm{A}, \llbracket \mathrm{A} \rrbracket\rangle \vdash \mathrm{A} / \mathrm{B} \quad\langle\mathrm{B}, \llbracket \mathrm{B} \rrbracket\rangle \vdash \mathrm{B}}{\langle\mathrm{A} \mathrm{B}, \llbracket \mathrm{A} \rrbracket \llbracket \mathrm{B} \rrbracket\rangle \vdash \mathrm{A}} / \mathrm{E} \\
\frac{\langle\mathrm{B}, \llbracket \mathrm{B} \rrbracket\rangle \vdash \mathrm{B} \quad\langle\mathrm{A}, \llbracket \mathrm{A} \rrbracket\rangle \vdash \mathrm{B} \backslash \mathrm{A}}{\langle\mathrm{B} \mathrm{A}, \llbracket \mathrm{A} \rrbracket \llbracket \mathrm{B} \rrbracket\rangle \vdash \mathrm{A}} \backslash \mathrm{E}
\end{gathered}
$$

\section{(16) Function composition}

$$
\frac{\langle\mathrm{A}, \llbracket \mathrm{A} \rrbracket\rangle \vdash \mathrm{A} / \mathrm{B} \quad\langle\mathrm{B}, \llbracket \mathrm{B} \rrbracket\rangle \vdash \mathrm{B} / \mathrm{C}}{\langle\mathrm{A} \mathrm{B}, \llbracket \mathrm{A} \rrbracket \circ \llbracket \mathrm{B} \rrbracket\rangle \vdash \mathrm{A} / \mathrm{C}} \mathrm{FC}
$$

\section{Extraposition rule}

$$
\frac{\langle\mathrm{A}, \llbracket \mathrm{A} \rrbracket\rangle \vdash \mathrm{A} / \mathrm{B} \quad\langle\mathrm{B}, \llbracket \mathrm{B} \rrbracket\rangle \vdash \mathrm{B} \quad\langle\mathrm{C}, \llbracket \mathrm{C} \rrbracket\rangle \vdash(\mathrm{A} / \mathrm{B}) \backslash(\mathrm{A} / \mathrm{B})}{\langle\mathrm{A} \mathrm{B} \mathrm{C}, \llbracket \mathrm{C} \rrbracket \llbracket \mathrm{A} \rrbracket \llbracket \mathrm{B} \rrbracket\rangle \vdash \mathrm{A}} \operatorname{Extp}
$$

The rules in (14), (15), and (16) are standard in CCG. We use (14) to introduce lexical items into derivations, where $\tau$ is a function assigning lexical items syntactic categories. (17) is added so that we will be able to handle the displacement of the relative clause away from its host on the left of the noun phrase to the right of the noun phrase (it is therefore similar to the Right-Wrap rule of (Bach 1979)). Admittedly, such a rule is ad hoc, though, in principle, it should handle other constructions involving displacement around a noun phrase, e.g., degree constructions.

These rules constitute the syntactic half of the framework. For the semantics, we adopt the use of contexts from de Groote (2006). Contexts are sets of individuals that are updated during the discourse so that anaphoric expressions may make reference to the referents of their antecedents via the contexts they take as their arguments. In general, we assume that every atomic type in the type of a $\lambda$-term representing a denotation is parameterized by a context. To achieve such parameterization, unlike de Groote, we make use of the transformations of de Groote \& Kanazawa (2013), but set to contexts, rather than worlds (following Kobele 2015). Thus, we assume that lexical denotations that do not inherently rely on contexts can be lifted via a contextualization transformation. The contextualization and decontextualization transformations (which are parametrized by the types of their arguments) are given in (19) after two relevant type transformations are given in (18). Following de Groote (2006), $\gamma$ is the type of contexts.

\section{Type transformations}

a. $\frac{\overline{\mathrm{a}}:=\gamma \rightarrow \mathrm{a}}{\alpha \rightarrow \beta}:=\bar{\alpha} \rightarrow \bar{\beta}$

(a is atomic) 


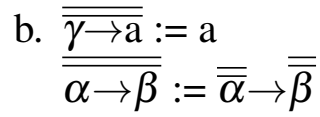

(a is atomic)

(19)

\section{Contextualization and decontextualization}

$$
\begin{aligned}
& \operatorname{con}_{\gamma \rightarrow \mathrm{a}} x:=\operatorname{decon}_{\gamma \rightarrow \mathrm{a}} x:=x \\
& \operatorname{con}_{\gamma \rightarrow \alpha \rightarrow \beta} P:=\left(\lambda x_{\bar{\alpha}} \cdot \operatorname{con}_{\gamma \rightarrow \beta}\left(\lambda c_{\gamma} \cdot P c\left(\operatorname{decon}_{\bar{\alpha}} x c\right)\right)\right) \\
& \operatorname{decon}_{\alpha \rightarrow \beta} P:=\left(\lambda c_{\gamma} \cdot\left(\lambda x_{\bar{\alpha}} \cdot \operatorname{decon}_{\beta}\left(P\left(\operatorname{con}_{\gamma \rightarrow \bar{\alpha}}\left(\lambda c^{\prime}{ }_{\gamma} \cdot x\right)\right)\right) c\right)\right)
\end{aligned}
$$

As an example, we assume the following Strawsonian meaning for the (nominative, neuter) German definite article das in (20).

$$
\llbracket d a s \rrbracket=\left(\lambda P_{\mathrm{e} \rightarrow \mathrm{t}} \cdot\left(l x_{\mathrm{e}} \cdot P x\right)\right)
$$

However, for our analysis of anaphora, in which we make use of contexts, we will assume the following lifted version of (20) as the meaning of das.

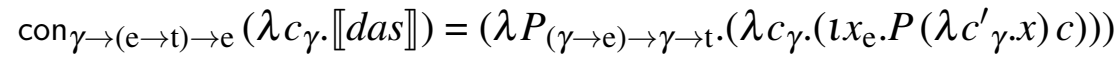

(21) provides a context-sensitive meaning for the definite article, which may combine with other context-sensitive meanings, e.g., the meaning of the article's restriction, via function application.

Having established this basic groundwork, we can present our analysis. We make use of the following two lexical entries corresponding to the weak and strong forms of the definite article. (We present these entries as though they were axioms in a derivation.)

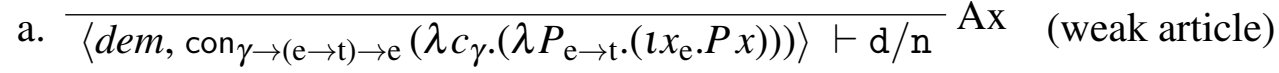
b. $\overline{\left\langle d e m, \operatorname{con}_{\gamma \rightarrow(\mathrm{e} \rightarrow \mathrm{t}) \rightarrow \mathrm{e}}\left(\lambda c_{\gamma} \cdot\left(\lambda P_{\mathrm{e} \rightarrow \mathrm{t}} \cdot\left(l x_{\mathrm{e}} \cdot P x\right)\right)\right)\right\rangle \vdash \mathrm{d} / \text { anaph }} \mathrm{Ax} \quad$ (strong article)

As shown in (22), all that differs between the strong and weak forms is the category of their restrictions. In addition to the categories $d$ and $n$ (these are usually called NP and $\mathrm{N}$ in the CCG literature), we introduce the category anaph, which, as we will show, is the category of an anaphoric noun phrase - the category which the strong form combines with. An anaphoric noun phrase is created by combining the lexical entry given in (23) with an ordinary noun phrase.

$$
\overline{\left\langle\operatorname{anaph},\left(\lambda P_{(\gamma \rightarrow \mathrm{e}) \rightarrow \gamma \rightarrow \mathrm{t}} \cdot\left(\lambda x_{\gamma \rightarrow \mathrm{e}} \cdot\left(\lambda c_{\gamma} \cdot P x c \& x c=\operatorname{sel} c\right)\right)\right)\right\rangle \vdash \operatorname{anaph} / \mathrm{n}} \mathrm{Ax}
$$

The meaning given in (23) takes an ordinary noun phrase meaning (i.e., a property) and constrains it to being identical to something in the context via the selection function sel. sel, the anaphora resolution function of de Groote, takes a context and returns one of its members. 
Article selection and anaphora

The last ingredient crucial to the analysis is the lexical entry we give for the head of the relative clause. The role of this lexical entry is to enable relative clauses to change the context in which a particular anaphoric expression-the relative pronoun-is interpreted. The meaning we give to this head, which we call ' $c$ ', is given in (24). To keep the presentation from getting too unwieldy, we use ' $E$ ' as an abbreviation for ' $\gamma \rightarrow \mathrm{e}$ ' and ' $\mathrm{T}$ ' as an abbreviation for ' $\gamma \rightarrow \mathrm{t}$ '.

$$
\begin{aligned}
& \llbracket c \rrbracket=\left(\lambda P _ { \mathrm { E } \rightarrow \mathrm { T } } \cdot \left(\lambda Q _ { ( \mathrm { E } \rightarrow \mathrm { T } ) \rightarrow \mathrm { E } } \cdot \left(\lambda A _ { ( \mathrm { E } \rightarrow \mathrm { T } ) \rightarrow \mathrm { E } \rightarrow \mathrm { T } } \cdot \left(\lambda N _ { \mathrm { E } \rightarrow \mathrm { T } } \cdot \left(\lambda x_{\mathrm{E}} .\right.\right.\right.\right.\right. \\
& \left.\left.\left.\left.\left.P\left(Q\left(\lambda y_{\mathrm{E}} \cdot\left(\lambda c^{\prime}{ }_{\gamma} \cdot A\left(\lambda z_{\mathrm{E}} \cdot\left(\lambda c^{\prime \prime} . N z c^{\prime}\right)\right) y\left\{x c^{\prime}\right\}\right)\right)\right)\right)\right)\right)\right)\right)
\end{aligned}
$$

Using this meaning, we give the lexical entry for $c$ in (25).

$$
\overline{\langle c, \llbracket c \rrbracket\rangle \vdash((\mathrm{d} / \text { anaph }) \backslash((\operatorname{anaph} / \mathrm{n}) \backslash(\operatorname{anaph} / \mathrm{n}))) /(\mathrm{s} / \mathrm{d})} \mathrm{Ax}
$$

Given (25), $c$ will combine with a gapped clause on its right and an article missing its restriction (the relative pronoun) on its left. It then combines with a noun phrase modifier (anaph) on its left, as well as a noun phrase, and combines them to be interpreted as the restriction of the aforementioned article. However, in the process, the context in which the noun phrase modifier is interpreted is replaced with a new context - that whose only member is the final individual argument of the relative clause (the argument introduced by ' $\lambda x_{\mathrm{E}}$ ' in the $\lambda$-term in (24)).

As an example, we illustrate the composition of the modified noun phrase in (26).

\section{(26) Haus von dem Fritz schwärmt}

The derivation goes as follows. First, the relative clause composes as in (27). We assume that the meaning of the preposition von is vacuous. (We leave out some of the types for reasons of space.)

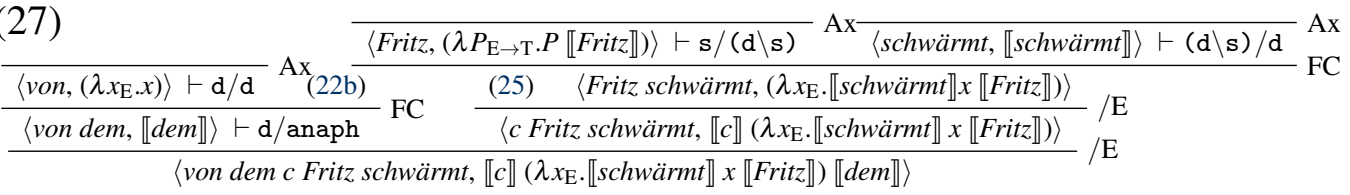

Once the relative clause is built, the extraposition rule combines it with its host, anaph, and the noun, as in (28).

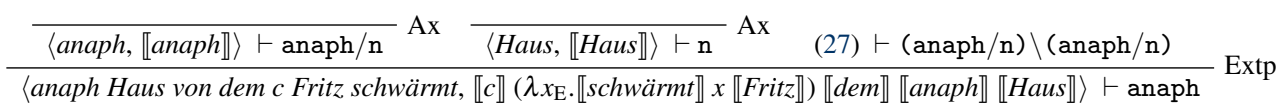

Given the meaning of $c$ in (24), the term given in (28) $\beta$-reduces to (29). 


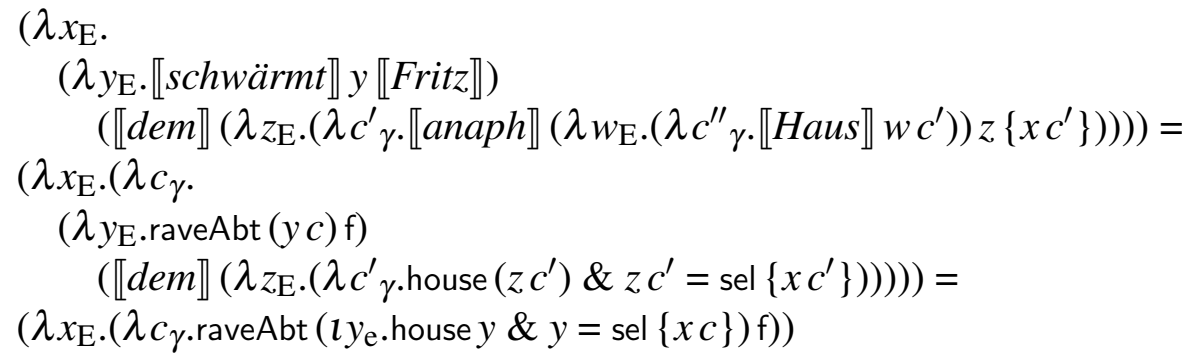

To better illustrate the meaning resulting from this derivation, we present the decontextualized version of the resulting $\lambda$-term in (30) (without the context parameter).

$$
\left(\lambda x_{\mathrm{e}} \text {.raveAbt }\left(l y_{\mathrm{e}} \text {.house } y \& y=\operatorname{sel}\{x\}\right) \mathrm{f}\right)
$$

Because sel is a choice function, sel $\{x\}$ reduces to $x$. Thus, (30) is a property true of those individuals which are houses that Fritz raved about.

Importantly, given the meaning of the relative clause head $c$ in (24), modification by anaph becomes crucial to achieving the desired property meaning associated with the relative clause. This is because the role of the relative clause itself is to shift the context with respect to which the noun phrase modifier is evaluated. Had some other, non-anaphoric modifier been present instead, the resulting property would have been a constant function from individuals to truth values (true if Fritz raves about the unique house; false otherwise). The role of anaph, therefore, is to set the relevant house as being identical to some antecedent - that provided by the argument introduced by $\llbracket c \rrbracket$ ( via the binder ' $\lambda x_{\mathrm{E}}$ '). Therefore, like cases of quantification, the role of the relative clause is to manipulate the context fed to an anaphoric expression. This, we argue, is what explains the use of the strong form, both in the relative pronoun and the matrix article, which must select for the category anaph to combine with the modified noun.

\section{Anaphora and dynamics}

We show here how the account we have developed for relative clauses extends to other cases of anaphora. We start with a simple case of anaphora to an indefinite, which was illustrated in (3) and is repeated here.

(3) Fritz wohnt seit Jahren in einem großen Haus. Er schärmt immer noch fritz lives since years in a big house he raves always still \{von dem, \#vom Haus.

from the from+the house

'Fritz has lifted in a big house for years. He still raves about the house.' 
Article selection and anaphora

To bring the current framework into a dynamic setting, we modify denotations to keep track, not only of contexts, but of continuations of the discourse, i.e., via arguments which are properties of contexts (de Groote 2006). As a result, not only will denotations be contextualized, but they will be parametrized by an argument of type $\gamma \rightarrow \mathrm{t}$. In addition, we must modify the compositional rules to account for this change, as well as add a new rule for updating the discourse (we depart here from some assumptions about composition normally made in CCG). We show how the grammar is modified with respect to function application in (31). In (32), we introduce the update rule.

Dynamic function application

$$
\begin{aligned}
& \frac{\langle\mathrm{A}, \llbracket \mathrm{A} \rrbracket\rangle \vdash \mathrm{A} / \mathrm{B} \quad\langle\mathrm{B}, \llbracket \mathrm{B} \rrbracket\rangle \vdash \mathrm{B}}{\left\langle\mathrm{A} \mathrm{B},\left(\lambda p_{\mathrm{T} \cdot} \llbracket \mathrm{A} \rrbracket p(\llbracket \mathrm{B} \rrbracket p)\right)\right\rangle \vdash \mathrm{A}} / \mathrm{E} \\
& \frac{\langle\mathrm{B}, \llbracket \mathrm{B} \rrbracket\rangle \vdash \mathrm{B} \quad\langle\mathrm{A}, \llbracket \mathrm{A} \rrbracket\rangle \vdash \mathrm{B} \backslash \mathrm{A}}{\left\langle\mathrm{B} \mathrm{A},\left(\lambda p_{\mathrm{T} \cdot} \cdot \mathrm{A} \rrbracket p(\llbracket \mathrm{B} \rrbracket p)\right)\right\rangle \vdash \mathrm{A}} \backslash \mathrm{E}
\end{aligned}
$$

\section{Update}

$$
\frac{\langle\mathrm{A}, \llbracket \mathrm{A} \rrbracket\rangle \vdash \mathrm{s} \quad\langle\mathrm{B}, \llbracket \mathrm{B} \rrbracket\rangle \vdash \mathrm{s}}{\langle\mathrm{A} . \mathrm{B}, \llbracket \mathrm{A} \rrbracket \circ \llbracket \mathrm{B} \rrbracket\rangle \vdash \mathrm{s}} \mathrm{Upd}
$$

The meaning for indefinite article einem in (3) is given in (33). (c::x is $c$ updated with $x$, i.e., $c \cup\{x\}$.)

$$
\begin{aligned}
& \llbracket e \text { inem } \rrbracket= \\
& \left(\lambda p_{\mathrm{T} \cdot} \cdot\left(\lambda P_{\mathrm{E} \rightarrow \mathrm{T}} \cdot\left(\lambda Q_{\mathrm{E} \rightarrow \mathrm{T}} \cdot\left(\lambda c_{\gamma \cdot}\left(\exists x_{\mathrm{e}} \cdot P\left(\lambda c^{\prime}{ }_{\gamma \cdot x}\right) c \& Q\left(\lambda c^{\prime}{ }_{\gamma \cdot x}\right) c:: x \& p c:: x\right)\right)\right)\right)\right)
\end{aligned}
$$

The composition of the meanings of sentences similar to those in (3) is given in (34)

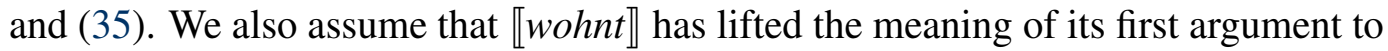
combine with the quantifier. (For reasons of space, we leave out the full derivation and just give the semantics.)

(34) $\llbracket$ Fritz, wohnt in einem Haus $\rrbracket=$ $\left(\lambda p_{\mathrm{T}} \cdot \llbracket\right.$ wohnt $\rrbracket p(\llbracket$ in $\rrbracket p(\llbracket$ einem $\rrbracket p(\llbracket$ Haus $\rrbracket p)))(\llbracket$ Fritz $\left.\rrbracket p)\right)=$ $\left(\lambda p_{\mathrm{T}} \cdot\left(\lambda c_{\gamma} \cdot\left(\exists x_{\mathrm{e}}\right.\right.\right.$.house $x \&$ live $\left.\left.\left.x \mathrm{f} \& p c:: x\right)\right)\right)$

(35) $\llbracket$ Fritz schwärmt von dem anaph Haus $\rrbracket=$ $\left(\lambda p_{\mathrm{T} \cdot} \llbracket \llbracket\right.$ schwärmt $\rrbracket p(\llbracket$ von $\rrbracket p(\llbracket$ dem $\rrbracket p(\llbracket$ anaph $\rrbracket p(\llbracket$ Haus $\rrbracket p))))(\llbracket$ Fritz $\left.\rrbracket p)\right)=$ $\left(\lambda p_{\mathrm{T}} \cdot\left(\lambda c_{\gamma}\right.\right.$.raveAbt $\left(l x_{\mathrm{e}}\right.$.house $\left.\left.\left.x \& x=\operatorname{sel} c\right) \mathrm{f} \& p c\right)\right)$

Updating (34) with (35) gives the meaning in (36). 


$$
\begin{aligned}
& \left(\lambda p _ { \mathrm { T } } \cdot \left(\lambda c_{\gamma} \cdot\right.\right. \\
& \left.\left.\quad\left(\exists x_{\mathrm{e}} \cdot \text { house } x \& \text { live } x \mathrm{f} \& \text { raveAbt }\left(l y_{\mathrm{e}} \cdot \text { house } y \& y=\text { sel } c:: x\right) \mathrm{f} \& p c:: x\right)\right)\right)
\end{aligned}
$$

Because the second sentence in the discourse (35) contains a definite description with the strong article, it makes non-trivial use of the context that is passed to it. The presence of anaph requires identifying the referent of the definite description dem anaph Haus with some individual in the context. The indefinite in (34) thereby serves as a possible antecedent.

In addition to basic cases involving anaphora to an indefinite antecedent, we may also account for cases of bridging, an example of which was introduced in (4) and is repeated here.

(4) Das Theaterstück missfiel dem Kritiker so sehr, dass er in seiner the play displeased the critic so much that he in his Besprechung kein gutes Haar \{ an dem, \#am $\}$ Autor ließ. review no good hair on the on+the author left

'The play displeased the critic so much that he tore the author to pieces in his review.'

(Schwarz 2009: 53, ex. 59)

As noted above, such cases of bridging can be distinguished from other similar cases that make use of the weak article. What we take to be crucial to examples such as (4) (following Schwarz 2009) is that the meaning of the noun phrase in the restriction of the definite article is relational. Autor, for example, has the meaning in (37).

$$
\llbracket \text { Autor } \rrbracket=\left(\lambda x_{\mathrm{E}} \cdot\left(\lambda y_{\mathrm{E}} \cdot\left(\lambda c_{\gamma} \cdot \text { authorOf }(x c)(y c)\right)\right)\right)
$$

Moreover, we assume that, in addition to the meaning for anaph introduced above, it may also have the meaning in (39). Such a meaning is available via a version of the iota type shift of Partee (1987), assimilated to the current grammar, in which meanings are contextualized, and the category of anaph is anaph $/ \mathrm{n}$.

$$
\begin{aligned}
& \text { iota }:=\left(\lambda A_{(\mathrm{E} \rightarrow \mathrm{T}) \rightarrow \mathrm{E} \rightarrow \mathrm{T} \cdot} \cdot\left(\lambda R_{\mathrm{E} \rightarrow \mathrm{E} \rightarrow \mathrm{T}} \cdot R\left(\lambda c_{\gamma} \cdot\left(l x_{\mathrm{e}} \cdot A\left(\lambda y_{\mathrm{E}} \cdot\left(\lambda c^{\prime}{ }^{\prime} \cdot 1\right)\right)\left(\lambda c^{\prime \prime} \gamma_{\cdot} \cdot x\right) c\right)\right)\right)\right) \\
& \text { iota } \llbracket \text { anaph } \rrbracket=\left(\lambda R_{\mathrm{E} \rightarrow \mathrm{E} \rightarrow \mathrm{T}} \cdot R \text { sel }\right)
\end{aligned}
$$

Making use of the type shift in (38), we can give anaph the additional lexical entry in (40).

$$
\overline{\langle\text { anaph, (iota } \llbracket a n a p h \rrbracket)\rangle \vdash \operatorname{anaph} / \mathrm{n}} \mathrm{Ax}
$$

As a result of this second meaning for anaph, dem anaph Autor composes as in (41).

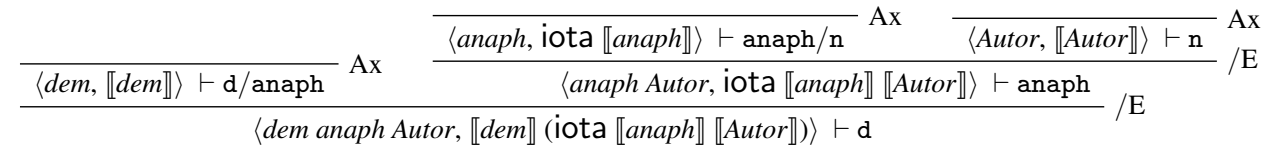


Article selection and anaphora

The meaning resulting from (41) can be seen to $\beta$-reduce to (42).

$$
\left(\lambda c_{\gamma} \cdot\left(l x_{\mathrm{e}} \cdot \text { authorOf }(\operatorname{sel} c) x\right)\right)
$$

In order for (41) to occur felicitously in a discourse, then, some individual which has a unique author must have been introduced into the context. Apparently, this is the case in (4).

To sum up, what we have shown is that the meaning of anaph that made it serviceable to the analysis of relative clauses given in the previous section extends straightforwardly to an account of its use in more conventional anaphoric contexts. The contexts we have illustrated here involve anaphora to an indefinite antecedent and anaphora to a bridged antecedent. We have left out other types of anaphora, for example, that which is interpreted as bound in the scope of a distributive quantifier. jedes in (5) above was such a case, and we leave its analysis out for reasons of space. However, the extension would be simple, given the tools we have introduced here. ${ }^{3}$

\section{Structural evidence}

Before concluding, we note some structural evidence for the current proposal based on morphological variation in the expression of anaphora in German. Such evidence comes from the fact that the lexical item anaph, which we have assumed is covert in our analysis, appears to have an overt allomorph in the prenominal modifier selb('same').

First, we note that selb- is available as a modifier in basic anaphoric contexts like (43), in which the definite description is anteceded by an indefinite.

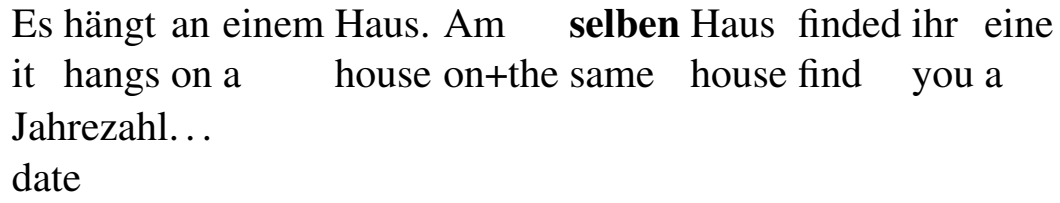

Indeed, both the form present in (43)_am selben Haus - and the form involving the strong article-an dem Haus - are felicitous in the context in (43). Therefore, the modifier anaph is either overt and expressed as selb-, in which case the article itself is weak, or the modifier is covert, as in the cases discussed above, and the article is strong. We do not discuss the morphological processes behind this alternation here, but see Hanink (To appear) for a proposal.

3 The reader should consult de Groote 2006 for similar examples.

$4 \mathrm{http}$ ://www.geocaching.com/geocache/GC47BF5mmm-schmeiss-weg?guid=b467c1c0-2552-4fc58481-d58c9908da3f 
In addition to its appearance as a prenominal modifier in anaphoric contexts like (43), selb-, like the strong article, occurs in the presence of relative clauses. (44) illustrates this behavior.

(44) Fritz wohnt jetzt im selben Haus, von dem er schon seit Jahren fritz lives now intthe same house from the he already since years schwärmt.

raves

'Fritz now lives in the same house that he's been raving about for years.'

This example can be contrasted with that in (2), in which the article is strong, and selben is absent. Thus, selben and the strong article appear in free variation in the context in (44), just as they do in the context in (43), lending some support to the claim that they are allomorphs.

Moreover, the distribution of selb- is not free, but appears to be restricted in the ways noted for the strong article. Consider the example in (45), for instance, in which the strong article would also be infelicitous, due to the lack of a relational noun in its restriction.

\#Der Kühlschrank war so groß, dass der Kürbis problemlos im the fridge was so big that the pumpkin problemless in+the selben Gemüsefach untergebracht werden konnte. same vegetable drawer stored be could

'The fridge was so big that the pumpkin could easily be stored in the same crisper.'

Given the similarity between definite descriptions containing selb-and those with strong articles, it appears that selb- and anaph may be overt and covert variants of the same structural position. Even if they are not, strictly speaking, allomorphs, the examples presented in this section appear to provide evidence for the general availability of lexical items and structural positions in the noun phrase responsible for anaphora. Such facts lend some plausibility to our analysis, on which it is a separate category, rather than the definite article itself, that is the source of anaphora in strong forms of the article.

\section{Conclusion}

We started this paper by noting the observation in Schwarz 2009 that the weak versus strong article distinction in German separates not only apparently anaphoric from non-anaphoric cases, but determines which articles may appear in relative clauses, both as the relative pronoun, and as the matrix determiner that selects for 
Article selection and anaphora

the modified noun. We decided to analyze the general distinction as a structural one: strong articles select for the category anaph, from which they inheret presuppositions of anaphoricity. What we hope to have shown is that relative clauses can be understood, under this analysis, as constructions that manipulate the context available for anaphora of a definite description. In that sense, they are like indefinite noun phrases, which update the context globally during the discourse, and other quantificational expressions, which may update the contexts available to their scopes (see de Groote 2006). As a result, our analysis opens up the possiblity that languages make use of more than one strategy for forming relative clauses. There is, perhaps, a more conventional strategy, wherein relative clauses are formed in a manner similar to constituent questions - via the movement of a wh-phrase. The strategy which we have argued for here, however, involves the recruitment of another linguistic system: anaphora.

\section{References}

Bach, Emmon. 1979. Control in Montague grammar. Linguistic Inquiry 10(4). 515-531.

Barwise, Jon \& John Perry. 1983. Situations and Attitudes. Cambridge: MIT Press. Elbourne, Paul. 2005. Situations and Individuals. Cambridge: MIT Press.

de Groote, Philippe. 2006. Towards a Montagovian account of dynamics. In Masayuki Gibson \& Jonathan Howell (eds.), Semantics and Linguistic Theory (SALT) 16, 1-16. Ithaca, NY: Cornell. doi:10.3765/salt.v16i0.2952.

de Groote, Philippe \& Makoto Kanazawa. 2013. A note on intensionalization. Journal of Logic, Language and Information 22(2). 173-194. doi:10.1007/s10849013-9173-9.

Hanink, Emily. To appear. The German definite article and the 'sameness' of indices. Penn Working Papers in Linguistics 23.1.

Hawkins, John. 1978. Definiteness and Indefinites: A Study in Reference and Grammaticality Prediction. London: Croom Helm.

Kobele, Gregory M. 2015. Montagovian dynamics in three easy steps. Unpublished manuscript. University of Chicago.

Kratzer, Angelika. 1989. An investigation of the lumps of thought. Linguistics and Philosophy 12(5). 607-653.

Kratzer, Angelika. 1995. Stage-level and individual-level predicates. In Greg N. Carlson \& Francis Jeffry Pelletier (eds.), The Generic Book, chap. 2, 125-175. Chicago: University of Chicago Press.

Kratzer, Angelika. 1998. Scope or pseudoscope? Are there wide-scope indefinites? In Susan Rothstein (ed.), Events and Grammar 70 Studies in Linguistics and Philosophy, 163-196. Dordrecht: Kluwer Academic Publishers. 
Kratzer, Angelika. 2002. Facts: Particulars or information units? Linguistics and Philosophy 25. 655-670. doi:10.1023/A:1020807615085.

Partee, Barbara H. 1987. Noun-phrase interpretation and type-shifting principles. In Jeroen Groenendijk, Dick de Jongh \& Martin Stokhof (eds.), Studies in Discourse Representation Theory and the Theory of Generalized Quantifiers, 115-141. Dordrecht: Foris.

Schwarz, Florian. 2009. Two types of definites in natural language. Amherst: University of Massachussetts $\mathrm{PhD}$ dissertation.

Strawson, Peter. 1950. On referring. Mind 59(235). 320-344. doi:10.1093/mind/LIX.235.320.

Julian Grove

Department of Linguistics

University of Chicago

1115 E. 58th Street

Chicago, IL 60637

juliang@uchicago.edu
Emily Hanink

Department of Linguistics

University of Chicago

1115 E. 58th Street

Chicago, IL 60637

eahanink@uchicago.edu 